\title{
The Media and Women Reproductive Health Sensitization in Kenya
}

\author{
Mr. Wafula Nyongesa* \\ Masinde Muliro University of Science and Technology MMUST Kakamega, Kenya
}

*Corresponding Author: Mr. Wafula Nyongesa, Masinde Muliro University of Science and Technology MMUST Kakamega, Kenya

\begin{abstract}
Women in Kenya face several reproductive health issues. Access to comprehensive sexual and reproductive health right is a basic human right. Women especially those living in poverty, face restricted or no access to information and services about their reproductive health and rights. Some of the barriers to sexual and reproductive health and rights include lack of information, discrimination, stigma, restrictive laws and policies, and entrenched traditions. This study investigates the role of mass media in positively affecting women's reproductive health behavior. Results of the study show that exposure to mass media has significant positive effect. The potential role of mass media in addressing women's reproductive health problems can be utilized through media messages targeted specifically at women
\end{abstract}

Keywords: mass media, women, reproductive health, gender.

\section{INTRODUCTION}

The coronavirus pandemic has put huge strain on Kenya's health system, and women's reproductive rights have taken a particular hit. Travel restrictions, the diversion of public healthcare towards Covid-19, the disruption in medical supply chains, including minimal coverage by the media on issues of women's reproductive health, have meant that women have been unable to receive timely care.

The mass media is believed to play a pivotal role in improving awareness on reproductive health and shaping the narrative positively. However, a considerable proportion of women do not have access to media. In 2011, the percentage of women aged between 15 and 49 who read a newspaper, watched television, and listened to radio at least once a week was only 4.7, 15.9, and 22.2 respectively (CSA AND ICF International, 2012). While more than two-thirds (68\%) of the women did not have access to any media. Only 1.75 had access to the three types of mass media. This study examines the roles of media in shaping reproductive health behaviour of women; and current situations in the utilization of mass media for reproductive health communication in Kenya.

In 1994, the International Conference on Population and Development (ICPD) was held in Cairo.

It defined reproductive health as the right to bodily and psychological integrity. Under this definition, Sexual and Reproductive Health encompasses, violence against women, safe motherhood, unwanted pregnancy and abortion, adolescent sexual and reproductive health, STDs/HIV/AIDS, fertility and or infertility and finally climacteric menopause (Heinrich Boll Foundation 2002).

Many international NGOs that participated observed that, by then, about half a million women died annually giving birth. It is also noted that, restrictions were still in place for contraception use and abortion. Women were resorting to informal providers, resulting into complications and even death (Burnell, 2011, ICPD '94 and PRB). Consequently, there has been a steady, albeit slow, wind of change sweeping across developing countries, creating a new awakening with regard to gender equality and giving men new perspectives over responsible fatherhood which also translates into safer motherhood. The 1995 United Nations Fourth World Conference on Women in Beijing also reinforced the need for gender equality and equity (Alcala, 1995).

\section{THEORETICAL REVIEW}

There are numerous theories that were developed to understand the pathways of change in human's health behaviour in response to media campaigns/interventions. Some of these are social cognitive 
theory, and the diffusion theory. According to social cognitive theory, adoption of behaviour is mainly influenced by outcome expectations and self-efficacy. Outcome expectation refers to a person's beliefs about the outcomes of the behaviour to be adopted and the perceived values of the behavioural outcomes. Increasing self-efficacy is another mechanism through which behaviour change can be achieved. The theory suggested four ways of increasing self-efficacy (Bandura, 1997). These are mastery experience, social modelling, improving physical and emotional states, and verbal persuasion. Learning from others is a powerful method through which individuals can change their attitude and behaviour. This learning takes place either formally or informally. In this regard, mass media plays vital role in behaviour change by bringing model characters through various broadcasts. Mass media is also a key in improving self-confidence of women or partners to effectively adopt a given reproductive health behaviour (Montgomery and Casterline, 1996).

Diffusion theory, emphasizing communication of innovations to bring about behavioural change, states that the pace of adopting an innovation depends on the characteristics of the innovations. This includes the knowledge required to use the innovation, its relative advantage, compatibility with values, norms and needs of potential adopters, complexity to understand and use, observability of the benefits, and risk associated with the invention (Greenhalgh et al., 2004). According to Rogers (2003), mass media plays key roles in the exchange of information and facilitation of discussion among partners on reproductive health issues that, in turn, expedites the adoption of a healthy reproductive behaviour.

The main focus of social cognitive and diffusion theories are modelling of responsible and effective health behaviours as well as facilitation of expansion of modern ideas and life styles related to seeking of health services. These theoretical perspectives are used to understand the roles of mass media in changing reproductive health behaviour of women in Kenya

\section{FINDINGS}

The study participants had variable understanding of good Reproductive Health, and more than half of them identified it as the ability of a person to perform sexual activity and procreate. However, some younger rural women believed that it is the absence of any disease or symptoms in reproductive organs. One of the rural participant said the more the number of off springs, the better the reproductive health of the mother). Two-thirds of participants had correct knowledge about the female reproductive organs and functions especially among urban residents. Most of the rural participants felt the need of better knowledge regarding women reproductive health and were willing to acquire the same. The majority of participants reiterated the deficiency of correct and easily accessible Reproductive Health information in the media

In both rural and urban areas, increase in cumulative media exposure correspondingly increased the proportion of women currently using contraceptives. While only $16 \%$ of women who had no exposure to family planning messages reported to have used contraceptives, the percentage had increased to $25 \%$ among those who were exposed to family planning messages from radio. Exposure to family planning messages from two sources (radio and television) and three media sources (radio, television, and print materials) increased the percentage of contraceptive users to 34 and 45 . In urban areas, too, the percentage of contraceptive users increased from $36 \%$ among women who had not been exposed to family planning messages to $42 \%, 55 \%$, and $59 \%$ among women who received family planning messages from one, two, and three sources, respectively.

There is noticeable difference between women in exposure to specific family planning messages. Nearly one-third (31\%) of urban women reported that they had no exposure to family planning messages compared to $74 \%$ in rural areas. The size of women who had no exposure to family planning messages was higher among women with no education and from economically poor households. Exposure to multiple media sources of family planning is very limited in both rural and urban areas. One-fifth (20\%), $5 \%$, and $2 \%$ of currently married women in rural areas obtained family planning message from one source (radio), two sources (radio and television), and three media sources (radio, television, and print materials), respectively. The respective figures are $13 \%, 37 \%$, and $19 \%$ for women in urban areas. Difference in cumulative media exposure is the function of variation in region, educational level, and socio-economic status.

In conclusion improvements in the reproductive health behaviour of the population in general and of currently married women in particular are mainly the function of socio-economic progresses. 
Although mass media programs play significant role in improving women's reproductive health behaviour, its effect on many reproductive health indicators is minimal. This is attributed to constraints associated with program design, implementation, and evaluation. This includes lack of clearly defined behavioural objectives and theories of change, absence of audience identification and segmentation, lack of tailored reproductive health communication messages, and lack of adequate knowledge and skill of preparing health communication messages.

\section{REFERENCES}

[1] Bandura, A. (1997). Self -Efficacy: The Exercise of control. New York: W. H. Freeman

[2] Greenhalgh, T., Robert, G., Macfarlane, F., Bate, P., Kryiakidou, O. (2004). Diffusion of

[3] Innovations in Service Organizations; Systematic Review and Recommendtions. Milbank Quarterly, 82(4)

[4] Koblinsky, M., Tain, F., Gaym, A., Karim, A., Carnell, M. and Tesfaye, S. (2010).Responding to the Maternal Health Care Challenge: The Ethiopian Health Extension Program. Ethiopian Journal of Health Development, 24(Special Issue 1):105-109.

[5] Montgomery, M. and Casterline, J. B. (1996). "Social Learning, Social Influence, and New Models of Fertility." Population and Development Review Supplement to Volume 22. Fertility in the United States: New Patterns, New Theories. Eds. John B. Casterline, Ronald D. Lee, and Karen A. Foote. New York: The Population Council. Pp. 151- 175.

[6] Rogers, E. M. (2003). Diffusion of Innovations. (5th ed.) New York: Free Press.

[7] United Nations, Fourth World Conference on Women, Action for Equity, Development and Peace, United Nations, Beijing, China, 1995.

[8] World Health Organization, Reproductive Health Strategy for the African Region 1998-2007, WHO Regional Office for Africa, Harare, Zimbabwe, 1998.

Citation: Mr. Wafula Nyongesa. "The Media and Women Reproductive Health Sensitization in Kenya". International Journal of Media, Journalism and Mass Communications (IJMJMC), vol 7, no. 1, 2021, pp. 0103 doi: http://dx.doi.org/10.20431/2454-9479.0701001.

Copyright: (0) 2021 Authors. This is an open-access article distributed under the terms of the Creative Commons Attribution License, which permits unrestricted use, distribution, and reproduction in any medium, provided the original author and source are credited. 